\title{
HIV Replication, Immune Activation, and CD4 Depletion: What the Virus Spares is as Significant as What It Destroys
}

\section{Zvi Grossman*‡}

\author{
Address: Department of Physiology and Pharmacology, Sackler Faculty of Medicine, Tel-Aviv University, Tel Aviv, Israel, and Laboratory of \\ Immunology, NIAID/NIH, Bethesda, MD, USA \\ * Corresponding author $\ddagger$ Presenting author
}

from 2005 International Meeting of The Institute of Human Virology

Baltimore, USA, 29 August - 2 September 2005

Published: 8 December 2005

Retrovirology 2005, 2(Suppl I):SI48 doi:I0.1 I86/I742-4690-2-SI-SI 48

Early depletion of mucosal CD4 T cells does not appear to substantially compromise the regenerative capacity of the immune system. Analysis of in-vivo DNA labeling suggests that in the chronic phase, activated $\mathrm{T}$ cells mainly arise in local proliferation bursts that resemble antigendriven responses. Most viral replication likely occurs in such bursts. Indirect evidence suggests that cytopathic effects of the virus in this context are selective and that memory cell regeneration is spared.

This and other observations question the validity of proposed mechanisms that directly link disease progression during the chronic phase to early mucosal depletion. I suggest that, paradoxically, both this early depletion and activation-induced lymphocyte turnover, while contributing to the pathogenic process in the long run, may also serve to control the rates of viral replication and evolution. 